\title{
The Role of Interleukin-1, Interleukin-6, and Glia in Inducing Growth of Neuronal Terminal Arbors in Mice
}

\author{
Clare L. Parish, ${ }^{*}$ David I. Finkelstein, ${ }^{*}$ Wanida Tripanichkul, Abhay R. Satoskar, John Drago, and \\ Malcolm K. Horne \\ Neurosciences Group, Department of Medicine, Monash University, Monash Medical Centre, Clayton 3168, Australia
}

\begin{abstract}
After injury to the substantia nigra pars compacta (SNpc), remaining neurons sprout to ensure normal dopamine delivery to the striatum. The consequent striatal reinnervation is highly regulated, with remaining cells sprouting so that density of dopamine terminals returns to normal. Sprouting as a result of injury is accompanied by a strong glial response; however, it is difficult to know whether this response is as a result of the injury or whether it is aiding in the sprouting. The two cytokines interleukin-1 (IL-1) and interleukin-6 (IL-6) are important modulators of the glia response. This study demonstrates their role in regulating the sprouting of dopaminergic neurons and the associated glia response as a means to examine the role of glia in sprouting. Sprouting was induced by 6-hydroxydopamine lesions of the SNpc and by haloperidol treatment (in the ab-
\end{abstract}

sence of injury). In wild-type animals, sprouting in association with microglial and astrocyte proliferation followed partial lesions of the SNpc and haloperidol treatment. Neither treatment evoked sprouting or glia proliferation in the type I IL-1 receptordeficient mice, whereas in IL-6-deficient mice, both treatments resulted in glial proliferation but not sprouting. We conclude that IL-1 plays a role in modulating glia proliferation and thereby guidance and trophic factors for new fibers, whereas IL-6 may be important in triggering the outgrowth of new fibers. This study demonstrates that these cytokines play an important role in plasticity and regeneration that is separate from the inflammatory response associated with brain injury.

Key words: interleukin-1; interleukin-6; regeneration; sprouting; haloperidol; lesioning; glia
After injury to the substantia nigra pars compacta $(\mathrm{SNpc})$, dopaminergic neurons sprout to form new branches and synapses (Onn et al., 1986; Thomas et al., 1994; Blanchard et al., 1995, 1996; Cheng et al., 1998; Ho and Blum, 1998; Batchelor et al., 1999; Liberatore et al., 1999; Finkelstein et al., 2000; Parish et al., 2001). Although this sprouting is accompanied by a glia response, it is difficult to know whether glia play an obligatory role in sprouting or are present because lesions induce an inflammatory response disrupting the blood-brain barrier and thereby causing a glia reaction and consequent upregulation of cytokines and growth factors. Recently, we reported that the $\mathrm{D}_{2}$ dopaminergic receptor $\left(\mathrm{D}_{2} \mathrm{R}\right)$ plays a central role in regulating $\mathrm{SNpc}$ arbor size and that pharmacological blockade of these receptors produces sprouting, thus providing an opportunity to examine the role of glia and cytokines in sprouting in the absence of trauma (Finkelstein et al., 2000; Parish et al., 2001).

Glia provide growth factors, guidance molecules, and a physical substratum for regenerating axons. The proinflammatory cytokine interleukin-1 (IL-1) is integral to the entry of microglia into inflamed areas, the activation of astrocytes, and regulation of the synthesis of growth factors (Giulian and Lachman, 1985; Lindholm et al., 1987; Lee et al., 1993). IL-1 can also induce neurons and glia to synthesize interleukin-6 (IL-6) (Benveniste et al.,

\footnotetext{
Received Dec. 26, 2001; revised May 16, 2002; accepted May 24, 2002.

This research was supported by grants from the Australian National Health and Medical Research Council. J.D. is a Logan Fellow at Monash University. We are grateful to Dr. R. Kitching for his enlightening discussions about interleukins and with the development of key concepts.

*C.L.P. and D.I.F. contributed equally to this work

Correspondence should be addressed to Prof. Malcolm Horne, Departments of Neurology Monash Medical Centre, Clayton Road, Clayton 3168, Australia. E-mail: malcolm.horne@med.monash.edu.au.

Copyright (C) 2002 Society for Neuroscience $\quad 0270-6474 / 02 / 228034-08 \$ 15.00 / 0$
}

1990; Sawada et al., 1992; Norris et al., 1994; Gadient and Otten, 1997). IL-1 stimulates the proliferation of astrocytes and thereby the consequent release of IL-6 (Giulian and Lachman, 1985; Lindholm et al., 1987; Lee et al., 1993; Ritchie et al., 1996) that is capable of modulating the differentiation and survival of neuronal cells (Nijsten et al., 1987; Satoh et al., 1988; Hama et al., 1991) and the gp130-mediated differentiation of astrocytes.

Although there is a view that brain expression of IL-1 only occurs in response to injury, there is increasing evidence that cytokines are expressed in normal adult brain. IL-1 is thought to have neuromodulatory functions related to central control of autonomic function (Watkins et al., 1999; Vitkovic et al., 2000; Szelenyi, 2001). Studies aiming to define the physiological functions of IL- 1 are difficult because the levels of IL- 1 mRNA and protein are at the limits of the resolution of current techniques (Vitkovic et al., 2000).

Glia are increased in the brains of human subjects treated with long-term antipsychotic agents (Selemon et al., 1999), and we observed increased glia in association with haloperidol-induced sprouting in rats (Finkelstein et al., 2001). In this study, we expanded on these observations by investigating whether a microglial and astrocytic reaction as well as specific cytokines are required for sprouting induced by $\mathrm{D}_{2} \mathrm{R}$ blockade. We used haloperidol treatment to induce sprouting and compared this and the glial response with the extent of sprouting that followed a lesion of the SNpc produced by 6-hydroxydopamine (6-OHDA). Haloperidol and 6-OHDA were also administered to type I interleukin-1 receptor knock-out [IL-1R(-/-)] and interleukin-6 knock-out [IL-6(-/-)] mutant mouse and the glial reaction and extent of sprouting compared with that induced in wild-type (WT) mice. It was anticipated that these mutant mice would have an attenuated microglia and/or astrocytic responses. Further- 
more, if a glia response were an essential requisite for sprouting, we would also predict that these mutants should have impaired sprouting.

\section{MATERIALS AND METHODS}

All methods conformed to the Australian National Health and Medical Research Council published code of practice for the use of animal research and was approved by the Monash University Animal Ethics Committee.

IL-6(-/-) were purchased from the Australian National University animal house. They were generated on a hybrid C57BL/6 and $129 / \mathrm{Sv}$ genetic background, and their generation and development were described in detail previously (Kopf et al., 1994). IL-1R(-/-)-deficient adult mice were also generated on a hybrid C57BL/6 and 129/Sv genetic background, and their generation and development were described in detail previously (Glaccum et al., 1997; Labow et al., 1997). The IL$1 \mathrm{R}(-/-)$ and IL-6(-/-) were backcrossed to C57BL/6, and, consequently, C57BL/6 mice were used as controls. Adult male mice were $10-12$ weeks at the commencement of experiments. IL-1R $(-/-)$ mice were genotyped using immunohistochemistry and IL-6(-/-) by an ELISA. In total, $54 \mathrm{WT}$ mice (25 untreated, five haloperidol, seven $4 \mathrm{~d}$ lesion, and 172 month lesion), $34 \mathrm{IL}-1 \mathrm{R}(-/-)$ mice (seven untreated, six haloperidol, seven $4 \mathrm{~d}$ lesion, and 142 month lesion), and 33 IL-6(-/-) mice (seven untreated, six haloperidol, six 4 d lesion, and 142 month lesion) were used in the subsequent experiments.

\section{Immunohistochemistry for tyrosine hydroxylase and dopamine transporter}

Animals were killed by an overdose of sodium pentobarbitone (Lethobarb; $0.35 \mathrm{mg} / \mathrm{gm})$ and perfused with $30 \mathrm{ml}$ of warmed $\left(37^{\circ} \mathrm{C}\right) 0.1 \mathrm{M} \mathrm{PBS}$, $\mathrm{pH} 7.4$, with heparin $(1 \mathrm{U} / \mathrm{ml})$, followed by $30 \mathrm{ml}$ of chilled $4 \%$ paraformaldehyde (Sigma, St. Louis, MO) and $0.2 \%$ picric acid in $0.1 \mathrm{~m}$ phosphate buffer $\left(4^{\circ} \mathrm{C}\right), \mathrm{pH}$ 7.4. The brains were then removed and left at $4^{\circ} \mathrm{C}$ overnight in $30 \%$ sucrose in PBS.

A 1 in 15 series of $16 \mu \mathrm{m}$ sections was cut in the coronal plane through the striatum. Sections were mounted directly onto slides coated with $0.1 \%$ chrome alum and $1 \%$ gelatin in water and then stored at $-70^{\circ} \mathrm{C}$ until required. A 1 in 2 series of coronal sections $(50-\mu \mathrm{m}$-thick) were cut through the SNpc.

Dopamine transporter (DAT) immunohistochemistry was used to identify dopaminergic terminals in the caudate putamen $(\mathrm{CPu})$ for stereological estimates of terminal density, and tyrosine hydroxylase (TH) immunohistochemistry identified dopaminergic neurons within the SNpc. Counts were made of both SNpc cell numbers and terminal density as described previously (Parish et al., 2001). A second series through the $\mathrm{SNpc}$ was mounted onto chrome alum-gelatinized slides for counter staining with neutral red (NR).

Glial fibrillary acidic protein immunohistochemistry. Sections through the striatum were processed for the glial fibrillary acidic protein (GFAP), a marker for astrocytes. Sections were fixed for $30 \mathrm{sec}$ in $10 \%$ neutral buffered formalin, followed by three washes in PBS. Sections were then left for $30 \mathrm{~min}$ in blocking buffer $(0.3 \%$ Triton $\mathrm{X}-100$ and $3 \%$ normal goat serum in PBS) and then incubated at $4^{\circ} \mathrm{C}$ overnight in rabbit polyclonal anti-GFAP (1:1000; Dako, Glostrup, Denmark) diluted in antibody diluent (0.3\% Triton X-100 and 1\% normal goat serum in PBS). Sections were washed three times in PBS and incubated with biotinylated secondary goat anti-rabbit IgG (1:500; Vector Laboratories, Burlingame, CA) for $1.5 \mathrm{hr}$ at room temperature, rinsed, and subsequently incubated in avidin peroxidase at a dilution of 1:5000 for $1 \mathrm{hr}$ at room temperature. Sections were then reacted with cobalt and nickel-intensified diaminobenzidine (DAB), mounted on microscope slides with a $0.5 \%$ gelatin solution, and counter stained in neutral red.

Griffonia simplicifolia isolectin $B_{4}$ histochemistry. A third series of striatal sections were processed histochemically with lectin from Griffonia simplicifolia isolectin $\mathrm{B}_{4}\left(\mathrm{GSI}-\mathrm{B}_{4}\right)$ conjugated to biotin (Sigma) for demonstration of microglia. Sections were fixed in $10 \%$ neutral buffered formalin for $30 \mathrm{sec}$ and rinsed in PBS. Sections were then incubated for $24 \mathrm{hr}$ at room temperature with biotinylated GSI-B ${ }_{4}$ diluted to $5 \mu \mathrm{g} / \mathrm{ml}$ in PBS with $1 \%$ Triton X-100. After three 10 min rinses in PBS, sections were incubated in avidin peroxidase (1:5000 dilution) (Sigma) for $1 \mathrm{hr}$, rinsed in PBS, and preincubated for $12 \mathrm{~min}$ in cobalt and nickel-intensified DAB solution (Sigma). This was followed by the addition of $3 \% \mathrm{H}_{2} \mathrm{O}_{2}(3.33 \mu \mathrm{l} / \mathrm{ml})$ into the DAB solution and reacted for 10-12 min. The sections then were rinsed in PBS and counterstained with neutral red.
Fractionator design for estimating total numbers of SNpc neurons, DAT-immunoreactive varicosities, and glia in the $\mathrm{CPu}$

The number of SNpc neurons (neutral red and TH-IR) and the density of DAT-IR terminals (DTs) in the dorsal CPu were estimated using methods described in detail previously (Gundersen et al., 1988; West et al., 1991; Coggeshall and Lekan, 1996; West et al., 1996; Finkelstein et al., 2000; Parish et al., 2001). The dorsal region of $\mathrm{CPu}$ was chosen for sampling because it predominantly receives the SNpc projection (Fallon and Moore, 1978; Bjorklund and Lindvall, 1984; Gerfen et al., 1987).

GFAP-IR astrocytes and GSI-B B $_{4}$ IR microglia were counted in $16-\mu \mathrm{m}-$ thick, 1 in 15 serial sections from the dorsal $400 \mu \mathrm{m}$ of the CPu. Counts were made at regular predetermined intervals $(x=250 \mu \mathrm{m} ; y=250 \mu \mathrm{m})$, and a counting frame $(125 \times 10 \mu \mathrm{m})$ was superimposed over the tissue and viewed under a $63 \times$ oil lens. Astrocytes and microglia were classified as immunoreactive cells possessing at least one process.

\section{Drug treatment groups}

A separate group of WT, IL-1R(-/-), and IL-6(-/-) mice received the reversible dopamine receptor antagonist haloperidol $(2.5 \mathrm{mg} / \mathrm{kg}$; Serenace; Sigma, Melbourne, Australia) in their drinking water continuously for 2 months.

\section{Lesioning}

Partial unilateral lesions of the SNpc were produced in a separate group of WT, IL-1R $(-/-)$, and IL- $6(-/-)$ mice using the neurotoxin 6-OHDA, as described previously (Parish et al., 2001).

\section{RESULTS}

\section{The nigrostriatal projection in IL-1R and IL-6 knock-out mice}

The number of SNpc neurons and DAT-IR terminals in the striatum were determined in WT, IL-1R ( $-/-)$, and IL-6 $(-/-)$ mice to calculate the size of the terminal arbors of SNpc neurons. ANOVAs with Tukey's post hoc tests were used with statistical differences set at the level of $p<0.05$.

\section{Stereology of the substantia nigra pars compacta}

The SNpc was delineated by staining with NR, and the number of NR-stained neurons in the SNpc was counted as described previously (Nelson et al., 1996; Parish et al., 2001). The number of TH-IR neurons in the SNpc were counted in alternate sections. The number of NR-stained SNpc neurons was similar in the WT, IL-1R(-/-), and IL-6(-/-) mice (Fig. 1A). As expected, the majority of neurons in the SNpc of WT, IL-1R(-/-), and IL-6 $(-/-)$ animals were TH-IR (Fig. $1 A)$.

\section{Stereology of DAT-labeled varicosities}

DAT-IR varicosities were counted as described in Materials and Methods, and density was determined as the number of varicosities estimated within the chosen counting area. We wanted to derive a representation of the average size of the terminal arbor of SNpc neurons for each genotype. The only way to measure the actual size of the arbor is to anterogradely fill and reconstruct individual axons, which is time consuming, and, consequently, only a small sample of the neuronal population can be analyzed this way. We developed and described a method for determining the terminal tree (TT) size as the density of DTs per TH-IR SNpc neuron $(\mathrm{NSNpc})$, having corrected for volume of $\mathrm{CPu}(\mathrm{VCPu})$ (Parish et al., 2001), which varied (although not statistically significant) between the genotypes. Using the following formula, a representative of the terminal tree size can be made, taking into account these volume differences. The formula for determining TT size was as follows: 


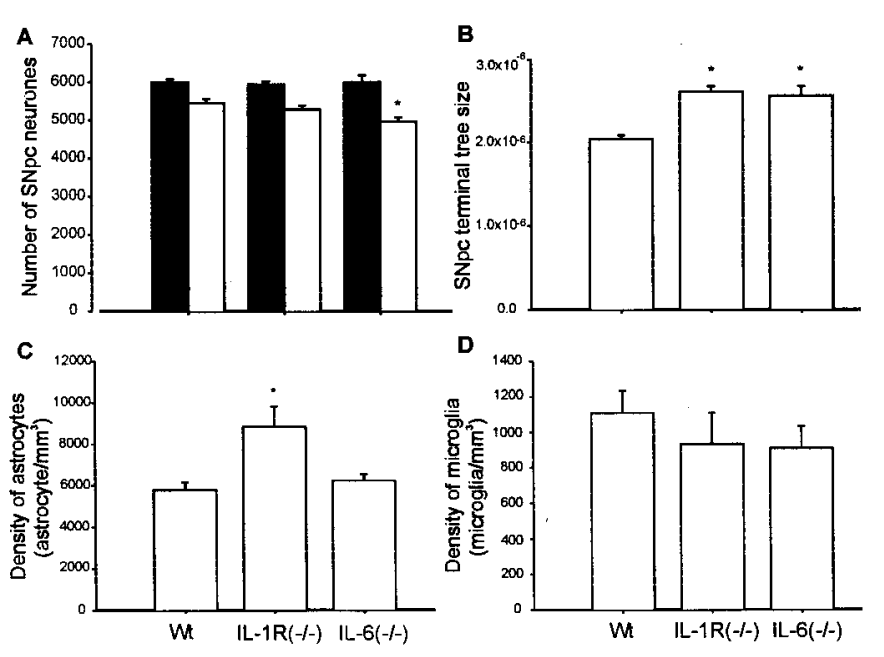

Figure 1. A, Histogram showing the number of SNpc neurons (mean \pm $\mathrm{SE})$ of WT, IL-1R(-/-), and IL-6(-/-) mice. Total counts of SNpc neurons stained with neutral red are shown in black, and TH-IR counts are shown in white. IL-6(-/-) mice had significantly less $(8.5 \%)$ TH-IR stained cells than WT mice. No significant difference was seen in any other groups. $B$, Histograms showing the terminal tree size of SNpc neurons in WT, IL-1R $(-/-)$, and IL-6 $-/-)$ mice (mean \pm SE). Terminal arbor size was significantly increased $(29$ and $25 \%)$ in IL-1R(-/-) and IL-6(-/-) mice, respectively. $C$ shows the density of astrocytes in which a significant increase in astrocytes $(34 \%)$ in the IL-1R(-/-) mice compared with WT. $D$, Density of microglia. No significant difference was seen in the density of microglia in any of the genotypes. ${ }^{*} p<0.05$.

$$
\mathrm{TT}_{\text {genotype }}=\left(\mathrm{DT}_{\text {genotype }} \times \mathrm{VCPu}_{\text {genotype }}\right) / \mathrm{NSNpc}_{\text {genotype }}
$$

Using this formula, TT of both IL-1R(-/-) and IL-6(-/-) mice were $\sim 25 \%$ larger than in WT (Fig. $1 B$ ).

\section{Stereology of GFAP-IR and GSI-B ${ }_{4}$-IR glia}

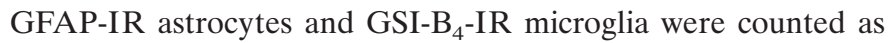
described Materials and Methods, and their density within the $\mathrm{CPu}$ was determined. The density of $\mathrm{GSI}_{-} \mathrm{B}_{4}-\mathrm{IR}$ microglia in the striatum was similar in each genotype. There was also no significant difference between the density of GFAP-IR astrocytes in WT and IL-6(-/-); however, a 34\% increase in density was seen in IL-1R(-/-) mice (Fig. 1 $A, B)$.

\section{Effects of the dopamine receptor antagonist haloperidol on WT, IL-1R(-/-), and IL-6(-/-) mice}

After haloperidol treatment, there was an increase in the size of the terminal arbors of SNpc neurons of WT mice (35\%), as observed previously (Parish et al., 2001). However, in both mutants, the size of the terminal tree was not altered by haloperidol treatment. It is noteworthy, however, that haloperidol treatment increased the TT of WT mice to a size similar to that observed in untreated mutants (Fig. 2A).

The density of both astrocytes and microglia increased in WT and IL-6(-/-) mice after haloperidol treatment. The increase in astrocytes was similar in both genotypes (46 and $43 \%$, respectively), whereas microglia more than doubled $(137 \%)$ in WT mice compared with a more modest $(43 \%)$ increase in IL-6(-/-) mice. In comparison, there was no changes in either astrocyte or microglial density of IL$1 \mathrm{R}(-/-)$ mice after drug treatment (Fig. $2 B, C)$. As with the size of the TT, the astrocyte density of IL-1R(-/-) mice was similar to those that resulted from haloperidol treatment of both WT and IL-6(-/-) mice. Microglia, on the other hand, were at similar levels to untreated WT mice but were unresponsive to haloperidol treatment (Fig. 2B,C).

\section{Effects of 6-OHDA lesioning of the SNpc on the terminal tree of dopaminergic neurons of IL-1R(-/-) and IL-6(-I-) mice}

The animals were killed at either $4 \mathrm{~d}$ or 2 months after the partial lesion, the number of SNpc neurons and DAT-IR varicosities in the dorsal $\mathrm{CPu}$ were counted, and the size of the TT was calculated. Stereological estimates of SNpc neuron numbers revealed lesion sizes ranging between 9 and 79\%. In animals with very large lesions, the number of neurons in the contralateral SNpc was also reduced, presumably attributable to diffusion of the toxin. In these cases, the contralateral hemisphere was included as an example of a small lesion size.

Animals killed $4 \mathrm{~d}$ after lesioning were used to assess the acute phase response of glia to injury. Both WT and IL-6(-/-) mice showed strong astrocytic and microglia responses $4 \mathrm{~d}$ after lesioning, the effect being greater in WT mice than IL-6(-/-) mice. The size of the response was proportional to the size of the lesion. There was no glial or astrocytic response as a consequence of lesioning IL-1R(-/-) (Fig. 3).

The relationship between glial and lesions was examined 2 months after lesioning. The density of microglia increased in proportion to the size of the lesion in both WT and IL-6(-/-) mice (Figs. 3, 4). In addition WT mice showed an exponential increase in astrocyte density, whereas no significant increase was observed in IL-6(-/-) mice. In IL-1R $(-/-)$ mutants, there was no response to lesioning and no relationship between microglial or astrocyte density to lesion size (Figs. 4, 5). Although the density of astrocytes was moderately elevated in unlesioned animals (compared with unlesioned WT or IL-6(-/-) mutants), lesioning did not elicit an additional elevation to the levels that were observed in WT or IL-6(-/-) mice with larger lesions. The very high GFAP counts recorded in acutely lesioned WT mice suggests that mice are capable of mounting a marked response and that the counts seen in the IL-1R(-/-) were not a ceiling maximum.

Figure 6 showed the responses of each genotype to the various manipulations (i.e., haloperidol, $4 \mathrm{~d}$ lesion, and 2 months after lesion) in which lesion data were pooled. This clearly illustrated the significant effects lesioning and haloperidol had on glia density in WT and IL-6(-/-) mice and highlighted the lack of effect in the IL-1R $(-/-)$ mice.

As observed previously in WT mice, terminal tree size increased through sprouting to maintain the density of DAT terminals at normal levels, at least until lesion size reaches $\sim 75 \%$ (Fig. 7A) (Finkelstein et al., 2000; Parish et al., 2001). In contrast, terminal density declined linearly in proportion to lesion size in the IL-1R(-/-) and IL-6(-/-) mice (Fig. $7 B, C)$. After a $40 \%$ lesion, terminal density fell by $\sim 50 \%$ of nonlesioned values in the IL-1R knock-out mice. Similarly, density was reduced by approximately one-third in the IL-6(-/-) mice after lesion sizes of $\sim 40 \%$. When the terminal tree was calculated in IL-1R $(-/-)$ and IL-6(-/-) mice, it was found that dopaminergic neurons do not sprout after lesions of the SNpc (Fig. $7 E, F$ ). Figure 8 illustrates the changes in the density of DAT-IR terminals in WT, IL-1R(-/-), and IL-6(-/-) mice 2 months after a partial SNpc lesion.

\section{DISCUSSION}

This study provides evidence that a microglial and astrocytic response, along with the cytokines IL-1 and IL-6, are required 

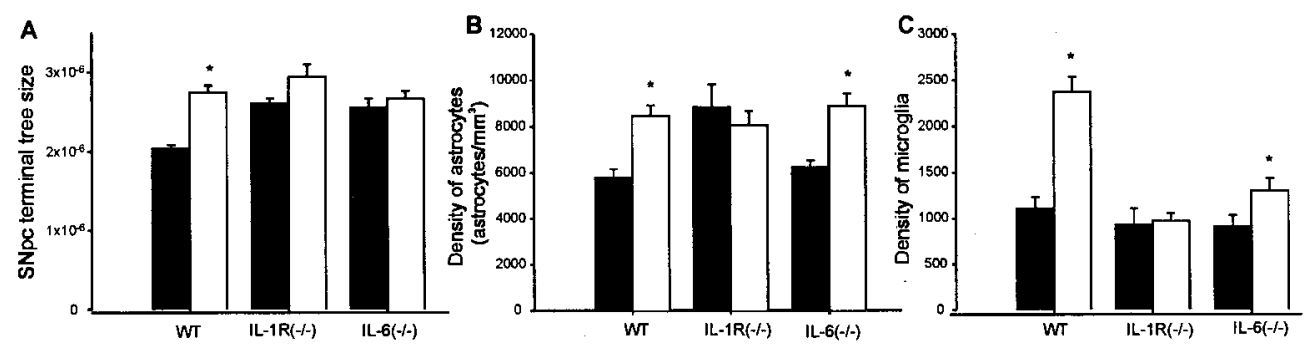

Figure 2. This figure compares the terminal tree sizes as well as microglia and astrocyte density of WT, IL-1R(-/-), and IL-6(-/-) mice before (black bars) and after (white bars) long-term haloperidol treatment. Mean \pm SE. $A$, Haloperidol caused a significant increase $(35 \%)$ in terminal tree size in WT animals but had no effect in the knock-out groups. $B$, A significant increase in the density of GFAP-IR astrocytes occurred in the WT and IL-6(-/-) mice after treat-

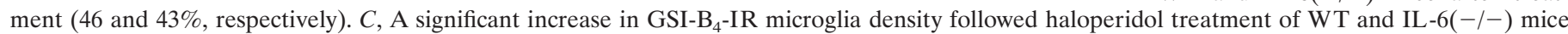
(137 and $43 \%$, respectively). Haloperidol had no effect on the density of either microglia or astrocytes in IL-1R $(-/-)$ mice. ${ }^{*} p<0.05$, significant differences from untreated animals.
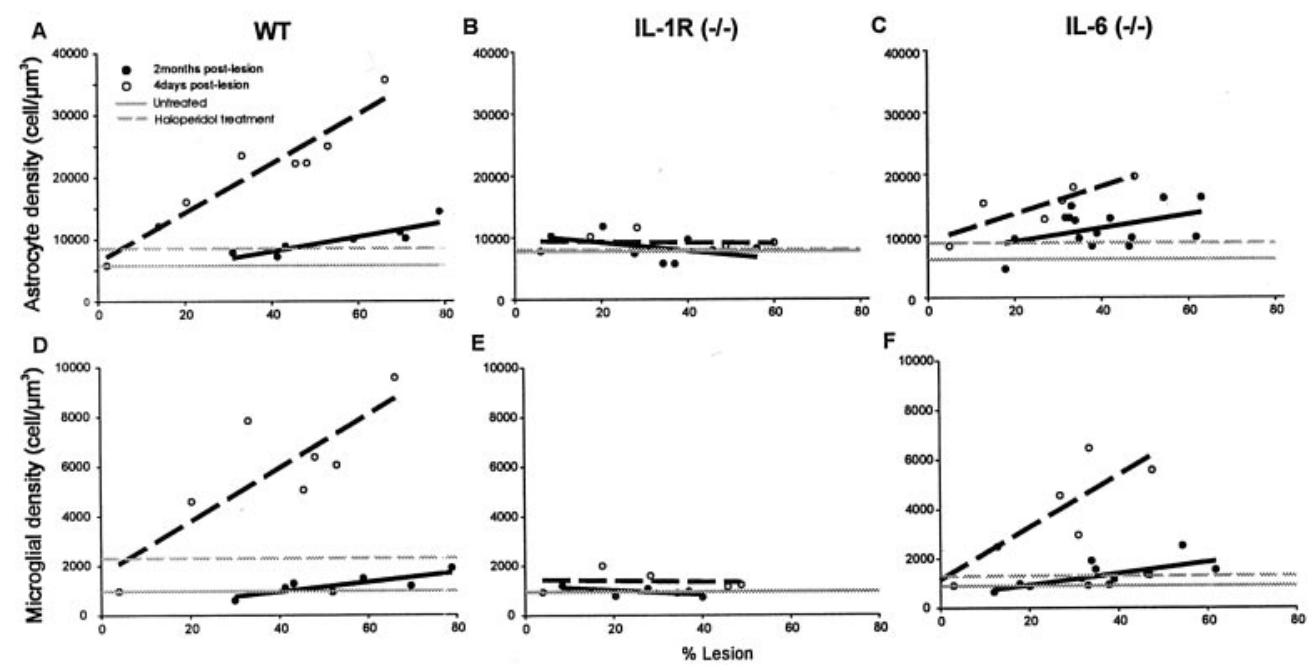

Figure 3. This figure illustrates the extent of microglia and astrocyte proliferation in WT, IL-1R(-/-), and IL$6(-/-)$ mice $4 \mathrm{~d}$ (black dotted line) and 2 months (black solid line) after varying $\mathrm{SNpc}$ lesion sizes. $A-C$ show the density of GFAP-IR astrocytes in WT, IL$1 \mathrm{R}(-/-)$, and IL-6(-/-) after lesion. Note the linear increase in microglia density as lesion size increases in the WT and IL-6(-/-) mice. $D-F$ show GSI-B ${ }_{4}$-IR microglia density in lesioned WT, IL-1R(-/-), and IL-6(-/-) mice, respectively. A steady increase in microglial density was evident in WT and IL-6(-/-) mice as lesion size increased. The solid gray line represents cell density in untreated animals, and the dotted gray line shows the effects of haloperidol on cell density. for a cytotrophic response to support sprouting of dopaminergic neurons. Haloperidol treatment resulted in a $35 \%$ increase in the size of the terminal tree, associated with a clear-cut increase in both astrocytes and microglia. This reaction was entirely free of the inflammatory response that typically follows acute injection of toxin into the SNpc, associated with disruption of the blood-brain barrier, removal of necrotic cellular debris, and initial axonal retraction. Similarly, at 2 months after lesions, the initial inflammatory response should be long gone because even the sprouting that follows this injury is near complete. Preliminary experiments showed a biphasic glial response to injury with an initial peak correlating to inflammation and a second later peak associated with supporting regenerating fibers (Finkelstein et al., 2001). Hence, the compensatory sprouting that follows a lesion of the $\mathrm{SNpc}$ could to be dependent on the associated robust microglia and astrocytes and the growth-promoting factors that they might provide.

This conclusion is supported by the findings from the study of $\operatorname{IL}-\operatorname{IR}(-/-)$ and IL-6(-/-) mice. In the case of the IL-1R $(-/-)$ line, there was no sprouting and no inflammatory response (microglial or astrocytic) elicited by either haloperidol treatment or lesioning. IL-1 stimulates the mobilization of microglia and proliferation of astrocytes and, with tumor necrosis factor $\alpha$, induces the synthesis of IL-6 (Giulian and Lachman, 1985; Lindholm et al., 1987; Lee et al., 1993; Ritchie et al., 1996) in both neurons and astrocytes (Benveniste et al., 1990; Sawada et al., 1992; Norris et al., 1994; Gadient and Otten, 1997). It is likely therefore that sprouting failed in the IL-1R $(-/-)$ mouse because of the absence of a glia reaction and the subsequent release of trophic factors to protect and support the SNpc fibers. Furthermore, there is evidence that IL-1 $\beta$ can stimulate surrounding non-neuronal cells to secrete neurotrophic factors, thus enhancing neurite regeneration from transected nerve terminals in cultured dorsal root ganglia explants (Horie et al., 1997). Activated microglia are the principal source of IL-1 (Giulian, 1987; Hetier et al., 1988), although it can be synthesized by astrocytes (Fontana et al., 1982) and neurons (Breder et al., 1988; Lechan et al., 1990; Tchelingerian et al., 1993). However, in the 1-methyl-4-(2'-methylphenyl)-1,2,3,6tetrahydropyridine hydrochloride denervated striatum, the predominant source of IL-1 is the GFAP-IR astrocytes and striatal neurons (Ho and Blum, 1998). The role of increased microglial and astrocyte density may be enhanced astroglial synthesis of dopaminergic neurotrophic factors such acid FGF (aFGF), basic FGF (bFGF), or glial cell line-derived neurotrophic factor (GDNF). Although these factors are increased 1 week after denervation of the striatum (Leonard et al., 1993), the induction of IL- $1 \alpha$ mRNA was not accompanied by induction of these factors, leading to the suggestion that IL- $1 \alpha$ could act directly on dopaminergic cells to induce plasticity (Ho and Blum, 1998). Our findings imply that through some mechanism, $\mathrm{D}_{2} \mathrm{R}$ blockade leads to IL-1 release, which in turns leads to a cascade of events that elicits both a glia response and sprouting. Previously, we showed the importance of the $\mathrm{D}_{2} \mathrm{R}$ in regulating the terminal arbor size of SNpc neurons (Parish et al., 2001). Although we speculated that this is mediated by the $\mathrm{D}_{2}$ autoreceptor, this is by no means certain. Recently, $\mathrm{D}_{2}$ Rs were shown on glia (Khan et al., 2001) and in the rat adrenal gland, in which the $\mathrm{D}_{2} \mathrm{R}$ regulates release of IL- 6 by noncatacholaminergic adrenal cells (Ritchie et al., 

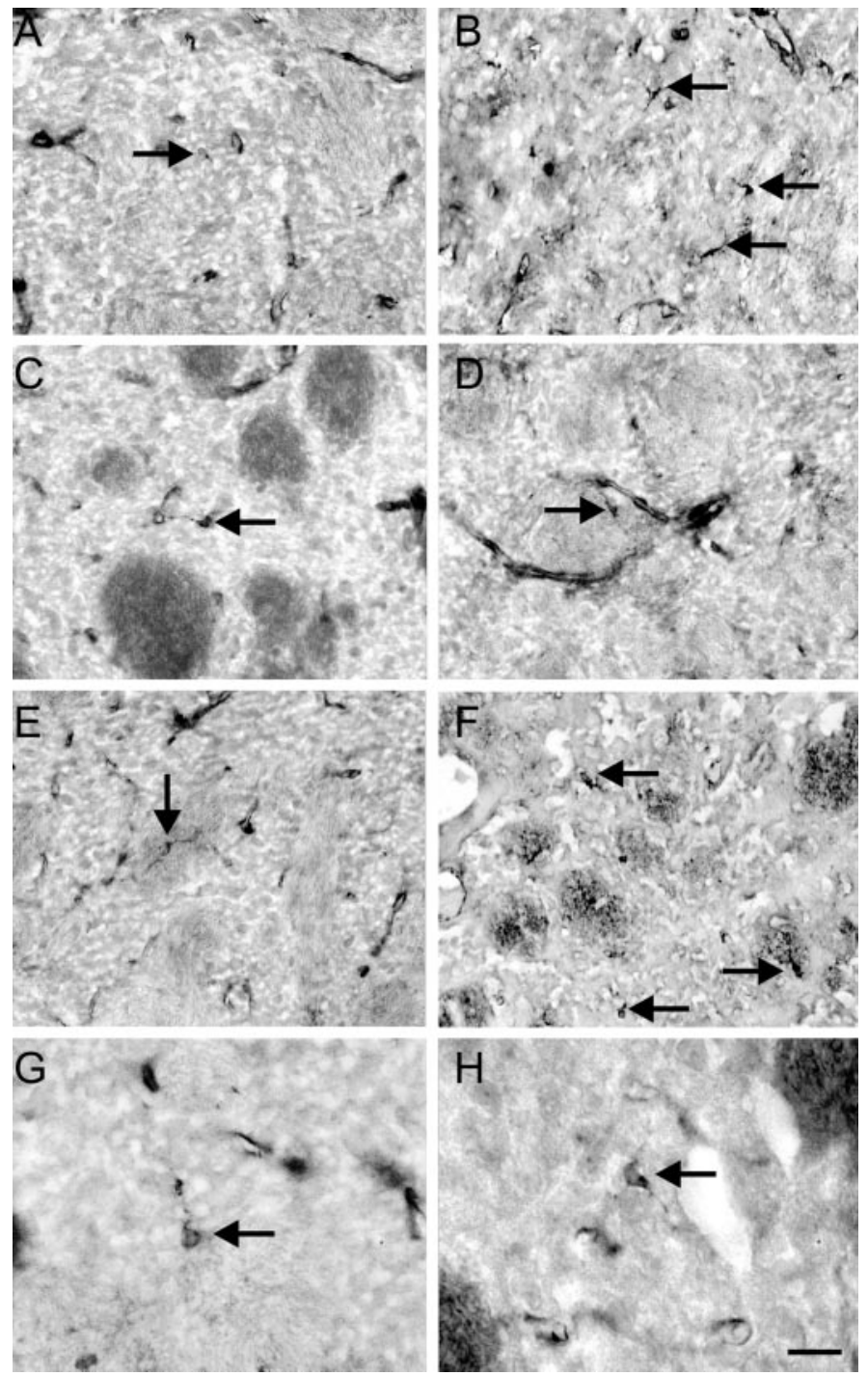

Figure 4. Photomicrographs showing examples of the density of GSIB4-IR microglia in untreated animals and those with $\sim 50 \%$ lesions of the SNpc from WT ( $A$, before; $D$; after), IL-1R(-/-) $(B, E)$, and IL-6(-/-) $(C, F)$ mice. Note the increase in density in WT and IL-6(-/-) mice, but it is not seen in IL-1R-deficient mice. Scale bar: $A-F, 25 \mu \mathrm{m} ; G, H, 10 \mu \mathrm{m}$.

1996). It is therefore possible that the $D_{2} R$ located on nonneuronal cells could regulate the release of cytokines. IL-1 may also have a specific cytotrophic or neuroprotective function, acting as a target-derived neurotrophic factor, because autoradiography studies have shown a distribution of IL-1 receptor binding in the substantia nigra (Farrar et al., 1987; Akaneya et al., 1995). In a double-label experiment, Ho and Blum (1998) showed that IL-1 receptor expression was found within tyrosine hydroxylaseimmunoreactive cells in the substantia nigra (Ho and Blum, 1998). Absence of sprouting in the IL-1R(-/-) mice is additional evidence that IL- $1 \alpha$ may be responsible for dopaminergic sprouting in mice after haloperidol treatment and after lesioning. Additional studies will be required to discriminate between the contributions to sprouting of IL-1 as a direct acting neurotrophic molecule as distinct from its indirect role as a cytokine that first mediates a microglial and astrocytic response and subsequent release of cytokines.

The response of the IL-6(-/-) mutant line to haloperidol and
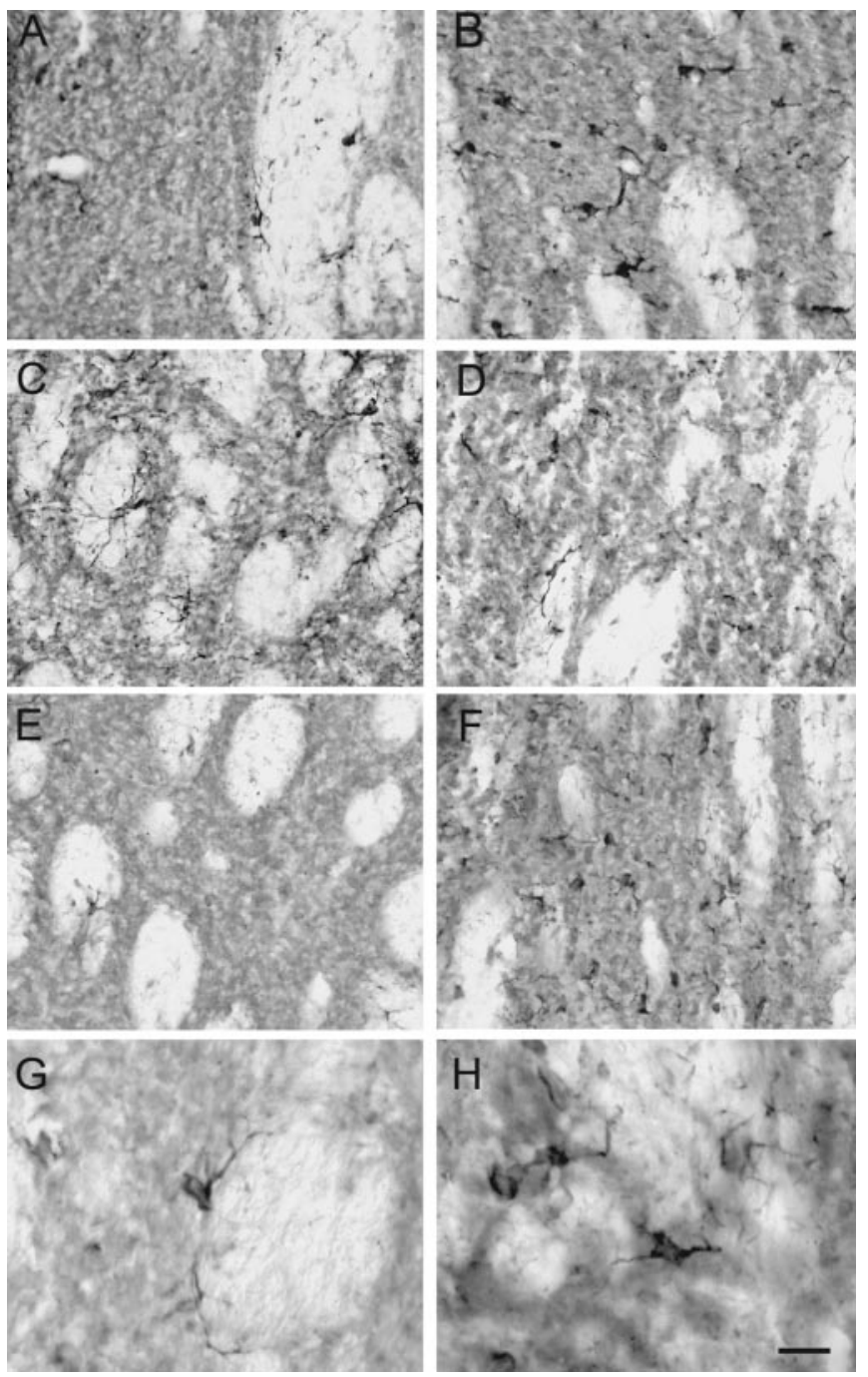

Figure 5. Photomicrographs showing examples of the density of GFAP-IR astrocytes in the dorsal striatum of untreated animals and those with $\sim 50 \%$ lesions of the SNpc from WT ( $A$, before; $D$, after), IL$1 \mathrm{R}(-/-)(B, E)$, and IL-6(-/-) $(C, F)$ mice. Note the increase in density in WT and IL-6(-/-) mice, but it is not evident in the IL-1R-deficient mice. Scale bar: $A-F, 25 \mu \mathrm{m} ; G, H, 10 \mu \mathrm{m}$.
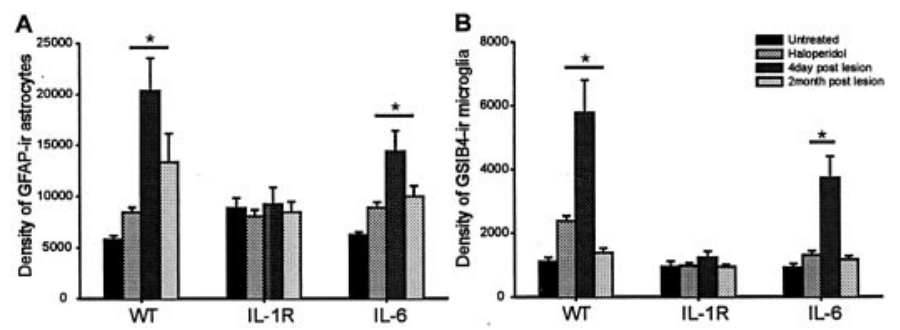

Figure 6. $A$ shows a histogram of the effects of haloperidol and lesioning on astrocyte density, and $B$ shows microglial density. Note that haloperidol and both $4 \mathrm{~d}$ and 2 months after lesion cause significant increases in astrocytes and microglial density in WT and IL-6(-/-) mice but have no effect on IL-1R (-/-) mice. An asterisk indicates statistical significance from untreated groups. 

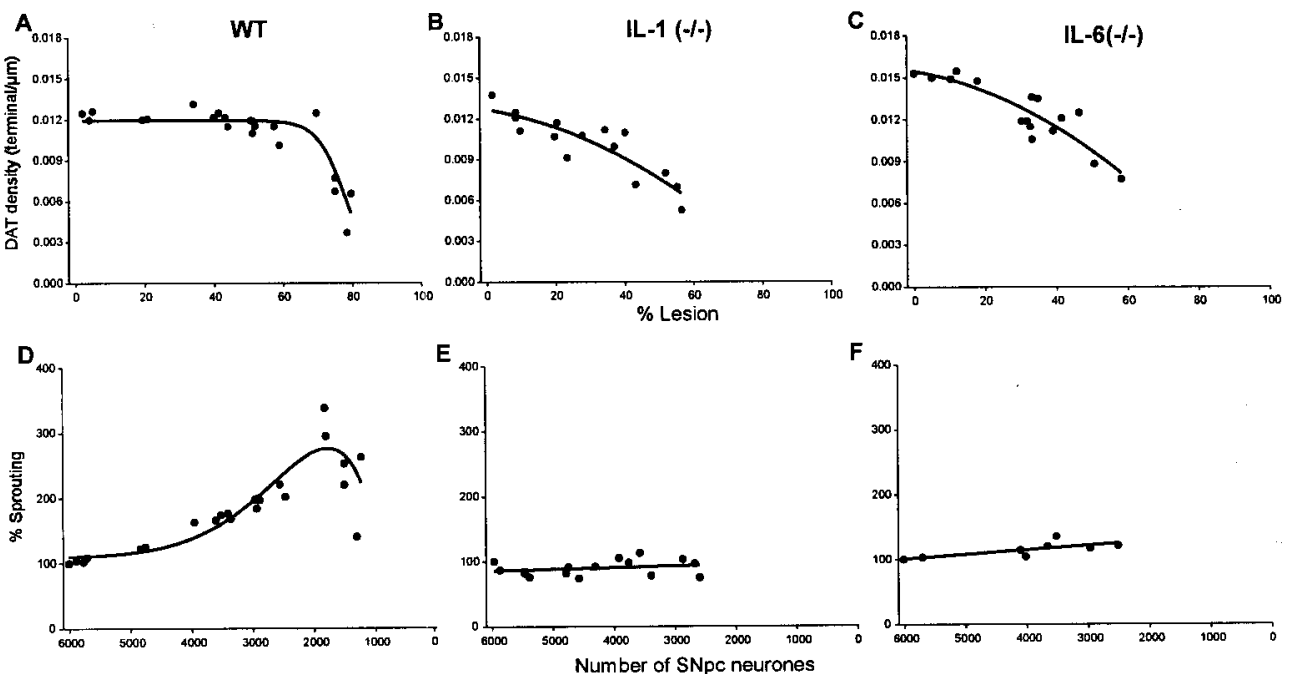

Figure 7. Plots of the density of DAT-IR terminals $(A-C)$ in the dorsal striatum against lesion size and the degree of regenerative sprouting $(E-G)$. $A$, Density of DAT-IR terminals in WT mice is maintained until $\sim 75 \% \mathrm{SNpc}$ neurons are lost, at which point density rapidly falls, presumably because remaining neurons can no longer compensate through sprouting. $D$ shows WT animals degree of sprouting, $100 \%$ representing normal tree size and values $>100 \%$ indicating a degree of sprouting. Note the significant degree of sprouting in WT animals when as few as 1500 $(25 \%)$ of neurons remain. $B$ shows density of DAT-IR terminals in IL$1 \mathrm{R}(-/-)$ mice with respect to varying lesion sizes. Note the persistent decline in density with increasing lesion size and the absence of sprouting in the remaining neurons in $E$. There was also a

rapid decline in DAT density in IL-6(-/ $)$ mice after lesioning $(C)$ and very minimal sprouting in the remaining neurons $(F)$. Note that each data point on the graphs represents one lesioned animal.
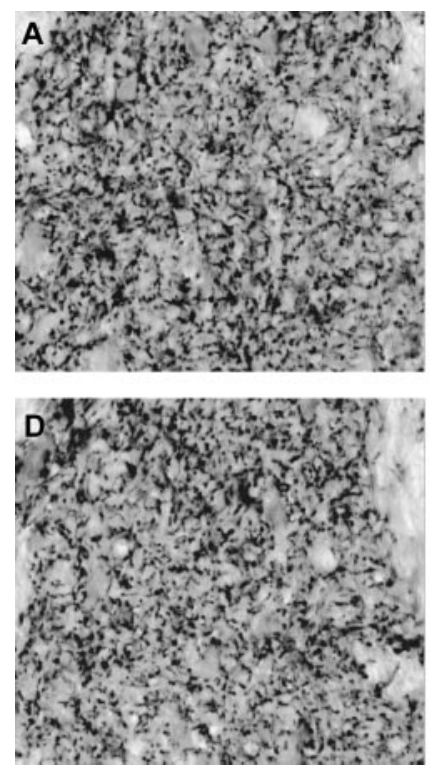
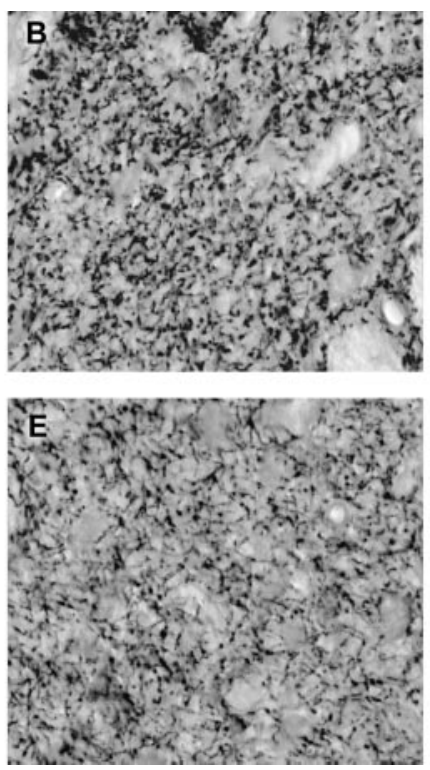
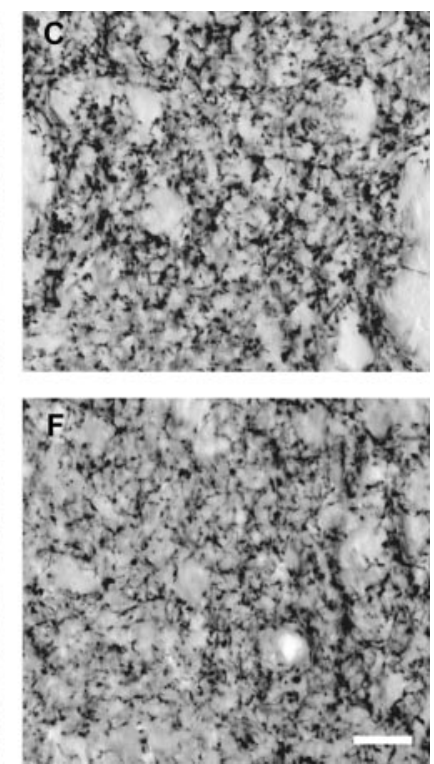

Figure 8. Photomicrographs showing examples of the density of DAT-IR terminals in untreated animals and those with $\sim 50 \%$ lesions of the SNpc from WT ( $A$, before; $D$, after), IL-1R $(-/-)$ $(B, E)$, and IL-6(-/-) $(C, F)$ mice. Note that density is maintained in WT mice after lesioning but is significantly reduced in both IL-1R- and IL-6deficient mice. Scale bar, $20 \mu \mathrm{m}$. injury was more complex than the IL-1R(-/-) mouse. The terminal tree size was unchanged, but there was a glial response after haloperidol treatment and at 2 months after lesioning. The increase in astrocyte density was commensurate with that observed in WT mice, but the microglial response, although significant, was muted compared with the WT mouse. This suggests that, although a glial response is essential, it is not on its own sufficient to elicit sprouting and that IL-6 must act at some other point to either trigger or sustain sprouting. The neuroprotective effects of IL-6 on mesenchephalic catecholamine neurons have been noted (Hama et al., 1991; Gadient and Otten, 1997), and it is possible that, in our lesion studies, the lack of IL-6 may have lead to a failure of protection of SNpc neurons. This, however, seems unlikely because lesions in these mutants were not larger than in WT, and it seems more likely that IL-6(-/-) was required to stimulate neurite formation. We reach this conclusion because, in the IL-6(-/-) mouse, the presence of the glia activity alone was not sufficient for axonal sprouting. After both haloperidol administration and lesioning, we observed both an astrocytic and microglial reaction in the IL- $6(-/-)$ line, but there was no increase in terminal tree in either case. One possibility is that, despite a glial reaction, the astrocytes in these animals cannot be induced to produce neurotrophic factors such as aFGF, bFGF, or GDNF. There is also a body of evidence that IL-6 itself functions as a neurotrophic agent. Although in vitro studies have long supported the idea that both astrocytes and microglia produce IL-6 (Frei et al., 1989; Lieberman et al., 1989) (Gottschall et al., 1995; Suzumura et al., 1996), more recent in vivo studies point toward neurons as an important source of this cytokine in both the CNS and the peripheral nervous system (Murphy et al., 1995, 1999; Arruda et al., 1998; Lemke et al., 1998; Munoz-Fernandez and Fresno, 1998; Hans et al., 1999; Streit et al., 2000). These studies have also shown a sustained upregulation of IL-6 mRNA in association with regeneration of adult facial motor neurons. There is also delayed regeneration of sensory axons in IL-6(-/-) mice (Zhong et al., 1999).

It is surprising that, during development, both $\mathrm{IL}-1 \mathrm{R}(-/-)$ and IL-6(-/-) mice form larger terminal trees than WT mice. 
Indeed, the effect of haloperidol on WT mice was to increase terminal tree comparable with that seen in IL-1R and IL-6 knock-out mice. However the lack of sprouting in the two mutants is not because the terminal tree was already at a maximum for dopaminergic neurons. An examination of the extent of sprouting that follows lesioning shows that, in the WT, the terminal tree can increase up to $300 \%$, whereas haloperidol induces only a $35 \%$ increase in tree size. Clearly, therefore, factors other than a notional maximum arbor limit are preventing additional sprouting in the two mutants. It is likely that these animals have enlarged terminal arbors as a result of compensatory effects that result from the absence of these cytokines. The astrocyte density was increased in the IL-1R(-/-) animals, and this (non-IL-1mediated effect) could be construed as being required to support the larger terminal trees in the IL-1R $(-/-)$ mice. However the IL-6(-/-) mice have similar sized terminal trees without the increased density of astrocytes, and so this seems an unlikely explanation. It does however imply that mechanisms that underlie developmental compensations may differ in the two mutants.

In summary, our findings suggest that the cytokines IL-1 and IL-6 play a central role in the regulation of axonal sprouting in both the unlesioned brain and after injury. In the absence of IL-1, there is neither astrocyte nor microglial proliferation and, consequently, no sprouting. Astrocyte, and to a lesser extent microglial, proliferation can occur without IL-6, but axonal sprouting does not occur, suggesting that IL-6 may have an additional more specific role as a trophic factor important in initiating or regulating neurite outgrowth. This study also raises the concern that immunosuppresion after stem cell therapy or injury may impair regeneration and repair.

\section{REFERENCES}

Akaneya Y, Takahashi M, Hatanaka H (1995) Interleukin-1 beta enhances survival and interleukin-6 protects against MPP + neurotoxicity in cultures of fetal rat dopaminergic neurons. Exp Neurol 136:44-52.

Arruda JL, Colburn RW, Rickman AJ, Rutkowski MD, DeLeo JA (1998) Increase of interleukin-6 mRNA in the spinal cord following peripheral nerve injury in the rat: potential role of IL- 6 in neuropathic pain. Brain Res Mol Brain Res 62:228-235.

Batchelor PE, Liberatore GT, Wong JY, Porritt MJ, Frerichs F, Donnan GA, Howells DW (1999) Activated macrophages and microglia induce dopaminergic sprouting in the injured striatum and express brainderived neurotrophic factor and glial cell line-derived neurotrophic factor. J Neurosci 19:1708-1716.

Benveniste EN, Sparacio SM, Norris JG, Grenett HE, Fuller GM (1990) Induction and regulation of interleukin- 6 gene expression in rat astrocytes. J Neuroimmunol 30:201-212.

Bjorklund A, Lindvall O (1984) Dopamine-containing systems in the CNS. In: Handbook of chemical neuroanatomy: classical transmitters in the CNS, Pt 1 (Bjorklund A, Hokfelt T, eds), pp 55-122. Amsterdam: Elsevier Science.

Blanchard V, Chritin M, Vyas S, Savasta M, Feuerstein C, Agid Y, Javoy-Agid F, Raisman-Vozari R (1995) Long-term induction of tyrosine hydroxylase expression: compensatory response to partial degeneration of the dopaminergic nigrostriatal system in the rat brain. J Neurochem 64:1669-1679.

Blanchard V, Anglade P, Dziewczapolski G, Savasta M, Agid Y, Raisman-Vozari R (1996) Dopaminergic sprouting in the rat striatum after partial lesion of the substantia nigra. Brain Res 709:319-325.

Breder CD, Dinarello CA, Saper CB (1988) Interleukin-1 immunoreactive innervation of the human hypothalamus. Science 240:321-324.

Cheng HW, Tong J, McNeill TH (1998) Lesion-induced axon sprouting in the deafferented striatum of adult rat. Neurosci Lett 242:69-72.

Coggeshall RE, Lekan HA (1996) Methods for determining numbers of cells and synapses: a case for more uniform standards of review. J Comp Neurol 364:6-15.

Fallon JH, Moore RY (1978) Catecholamine innervation of the basal forebrain. IV. Topography of the dopamine projection to the basal forebrain and neostriatum. J Comp Neurol 180:545-580.

Farrar WL, Kilian PL, Ruff MR, Hill JM, Pert CB (1987) Visualization and characterization of interleukin 1 receptors in brain. J Immunol 139:459-463.

Finkelstein DI, Stanic D, Parish CL, Tomas D, Dickson K, Horne MK
(2000) Axonal sprouting following lesions of the rat substantia nigra. Neuroscience 97:99-112.

Finkelstein DI, Parish CL, Stanic D, Borrelli E, Drago J, Horne MK (2001) The role of dopamine receptors in regulating the size of terminal arbours. In: International Basal Ganglia Society VII (Nicholson LFB, ed). New York: Plenum.

Fontana A, Kristensen F, Dubs R, Gemsa D, Weber E (1982) Production of prostaglandin $\mathrm{E}$ and an interleukin-1 like factor by cultured astrocytes and C6 glioma cells. J Immunol 129:2413-2419.

Frei K, Malipiero UV, Leist TP, Zinkernagel RM, Schwab ME, Fontana A (1989) On the cellular source and function of interleukin 6 produced in the central nervous system in viral diseases. Eur J Immunol 19:689-694.

Gadient RA, Otten UH (1997) Interleukin-6 (IL-6)—a molecule with both beneficial and destructive potentials. Prog Neurobiol 52:379-390.

Gerfen CR, Herkenham M, Thibault J (1987) The neostriatal mosaic. II. Patch- and matrix-directed mesostriatal dopaminergic and nondopaminergic systems. J Neurosci 7:3915-3934.

Giulian D (1987) Ameboid microglia as effectors of inflammation in the central nervous system. J Neurosci Res 18:155-171.

Giulian D, Lachman LB (1985) Interleukin-1 stimulation of astroglial proliferation after brain injury. Science 228:497-499.

Glaccum MB, Stocking KL, Charrier K, Smith JL, Willis CR, Maliszewski C, Livingston DJ, Peschon JJ, Morrissey PJ (1997) Phenotypic and functional characterization of mice that lack the type I receptor for IL-1. J Immunol 159:3364-3371.

Gottschall PE, Yu X, Bing B (1995) Increased production of gelatinase B (matrix metalloproteinase-9) and interleukin-6 by activated rat microglia in culture. J Neurosci Res 42:335-342.

Gundersen HJ, Bagger P, Bendtsen TF, Evans SM, Korbo L, Marcussen N, Moller A, Nielsen K, Nyengaard JR, Pakkenberg B, Sorensen FB, Vesterby A, West MJ (1988) The new stereological tools: disector, fractionator, nucleator and point sampled intercepts and their use in pathological research and diagnosis. APMIS 96:857-881.

Hama T, Kushima Y, Miyamoto M, Kubota M, Takei N, Hatanaka H (1991) Interleukin-6 improves the survival of mesencephalic catecholaminergic and septal cholinergic neurons from postnatal, twoweek-old rats in cultures. Neuroscience 40:445-452.

Hans VH, Kossmann T, Lenzlinger PM, Probstmeier R, Imhof HG, Trentz O, Morganti-Kossmann MC (1999) Experimental axonal injury triggers interleukin- 6 mRNA, protein synthesis and release into cerebrospinal fluid. J Cereb Blood Flow Metab 19:184-194.

Hetier E, Ayala J, Denefle P, Bousseau A, Rouget P, Mallat M, Prochiantz A (1988) Brain macrophages synthesize interleukin-1 and interleukin-1 mRNAs in vitro. J Neurosci Res 21:391-397.

Ho A, Blum M (1998) Induction of interleukin-1 associated with compensatory dopaminergic sprouting in the denervated striatum of young mice: model of aging and neurodegenerative disease. J Neurosci 18:5614-5629.

Horie H, Sakai I, Akahori Y, Kadoya T (1997) IL-1 beta enhances neurite regeneration from transected-nerve terminals of adult rat DRG. NeuroReport 8:1955-1959.

Khan ZU, Koulen P, Rubinstein M, Grandy DK, Goldman-Rakic PS (2001) An astroglia-linked dopamine D2-receptor action in prefrontal cortex. Proc Natl Acad Sci USA 98:1964-1969.

Kopf M, Baumann H, Freer G, Freudenberg M, Lamers M, Kishimoto T, Zinkernagel R, Bluethmann H, Kohler G (1994) Impaired immune and acute-phase responses in interleukin-6-deficient mice. Nature 368:339-342.

Labow M, Shuster D, Zetterstrom M, Nunes P, Terry R, Cullinan EB, Bartfai T, Solorzano C, Moldawer LL, Chizzonite R, McIntyre KW (1997) Absence of IL-1 signaling and reduced inflammatory response in IL-1 type I receptor-deficient mice. J Immunol 159:2452-2461.

Lechan RM, Toni R, Clark BD, Cannon JG, Shaw AR, Dinarello CA, Reichlin S (1990) Immunoreactive interleukin-1 beta localization in the rat forebrain. Brain Res 514:135-140.

Lee SC, Liu W, Dickson DW, Brosnan CF, Berman JW (1993) Cytokine production by human fetal microglia and astrocytes. Differential induction by lipopolysaccharide and IL-1 beta. J Immunol 150:2659-2667.

Lemke R, Hartig W, Rossner S, Bigl V, Schliebs R (1998) Interleukin-6 is not expressed in activated microglia and in reactive astrocytes in response to lesion of rat basal forebrain cholinergic system as demonstrated by combined in situ hybridization and immunocytochemistry. J Neurosci Res 51:223-236.

Leonard S, Luthman D, Logel J, Luthman J, Antle C, Freedman R, Hoffer B (1993) Acidic and basic fibroblast growth factor mRNAs are increased in striatum following MPTP-induced dopamine neurofiber lesion: assay by quantitative PCR. Brain Res Mol Brain Res 18:275-284.

Liberatore GT, Finkelstein DI, Wong JY, Horne MK, Porritt MJ, Donnan GA, Howells DW (1999) Sprouting of dopaminergic axons after striatal injury: confirmation by markers not dependent on dopamine metabolism. Exp Neurol 159:565-573.

Lieberman AP, Pitha PM, Shin HS, Shin ML (1989) Production of tumor necrosis factor and other cytokines by astrocytes stimulated with 
lipopolysaccharide or a neurotropic virus. Proc Natl Acad Sci USA 86:6348-6352.

Lindholm D, Heumann R, Meyer M, Thoenen H (1987) Interleukin-1 regulates synthesis of nerve growth factor in non-neuronal cells of rat sciatic nerve. Nature 330:658-659.

Munoz-Fernandez MA, Fresno M (1998) The role of tumour necrosis factor, interleukin 6 , interferon-gamma and inducible nitric oxide synthase in the development and pathology of the nervous system. Prog Neurobiol 56:307-340.

Murphy PG, Grondin J, Altares M, Richardson PM (1995) Induction of interleukin-6 in axotomized sensory neurons. J Neurosci 15:5130-5138.

Murphy PG, Borthwick LS, Johnston RS, Kuchel G, Richardson PM (1999) Nature of the retrograde signal from injured nerves that induces interleukin-6 mRNA in neurons. J Neurosci 19:3791-3800.

Nelson EL, Liang CL, Sinton CM, German DC (1996) Midbrain dopaminergic neurons in the mouse: computer-assisted mapping. J Comp Neurol 369:361-371.

Nijsten MW, de Groot ER, ten Duis HJ, Klasen HJ, Hack CE, Aarden LA (1987) Serum levels of interleukin-6 and acute phase responses. Lancet 2:921.

Norris JG, Tang LP, Sparacio SM, Benveniste EN (1994) Signal transduction pathways mediating astrocyte IL-6 induction by IL-1 beta and tumor necrosis factor-alpha. J Immunol 152:841-850.

Onn SP, Berger TW, Stricker EM, Zigmond MJ (1986) Effects of intraventricular 6-hydroxydopamine on the dopaminergic innervation of striatum: histochemical and neurochemical analysis. Brain Res 376:8-19.

Parish CL, Finkelstein DI, Drago J, Borrelli E, Horne MK (2001) The role of dopamine receptors in regulating the size of axonal arbors. J Neurosci 21:5147-5157.

Ritchie PK, Ashby M, Knight HH, Judd AM (1996) Dopamine increases interleukin 6 release and inhibits tumor necrosis factor release from rat adrenal zona glomerulosa cells in vitro. Eur J Endocrinol 134:610-616.

Satoh T, Nakamura S, Taga T, Matsuda T, Hirano T, Kishimoto T, Kaziro Y (1988) Induction of neuronal differentiation in PC12 cells by B-cell stimulatory factor 2/interleukin 6. Mol Cell Biol 8:3546-3549.
Sawada M, Suzumura A, Marunouchi T (1992) TNF alpha induces IL-6 production by astrocytes but not by microglia. Brain Res 583:296-299.

Selemon LD, Lidow MS, Goldman-Rakic PS (1999) Increased volume and glial density in primate prefrontal cortex associated with chronic antipsychotic drug exposure. Biol Psychiatry 46:161-172.

Streit WJ, Hurley SD, McGraw TS, Semple-Rowland SL (2000) Comparative evaluation of cytokine profiles and reactive gliosis supports a critical role for interleukin-6 in neuron-glia signaling during regeneration. J Neurosci Res 61:10-20.

Suzumura A, Sawada M, Marunouchi T (1996) Selective induction of interleukin-6 in mouse microglia by granulocyte-macrophage colonystimulating factor. Brain Res 713:192-198.

Szelenyi J (2001) Cytokines and the central nervous system. Brain Res Bull 54:329-338.

Tchelingerian JL, Quinonero J, Booss J, Jacque C (1993) Localization of TNF alpha and IL-1 alpha immunoreactivities in striatal neurons after surgical injury to the hippocampus. Neuron 10:213-224.

Thomas J, Wang J, Takubo H, Sheng J, de Jesus S, Bankiewicz KS (1994) A 6-hydroxydopamine-induced selective parkinsonian rat model: further biochemical and behavioral characterization. Exp Neurol 126:159-167.

Vitkovic L, Bockaert J, Jacque C (2000) "Inflammatory" cytokines: neuromodulators in normal brain? J Neurochem 74:457-471.

Watkins LR, Nguyen KT, Lee JE, Maier SF (1999) Dynamic regulation of proinflammatory cytokines. Adv Exp Med Biol 461:153-178.

West MJ, Slomianka L, Gundersen HJ (1991) Unbiased stereological estimation of the total number of neurons in the subdivisions of the rat hippocampus using the optical fractionator. Anat Rec 231:482-497.

West MJ, Ostergaard K, Andreassen OA, Finsen B (1996) Estimation of the number of somatostatin neurons in the striatum: an in situ hybridization study using the optical fractionator method. J Comp Neurol 370:11-22.

Zhong J, Dietzel ID, Wahle P, Kopf M, Heumann R (1999) Sensory impairments and delayed regeneration of sensory axons in interleukin6-deficient mice. J Neurosci 19:4305-4313. 